\title{
Saint-John Perse, Uccelli
}

\section{Emanuele Kanceff}

\section{(2) OpenEdition}

\section{Journals}

\section{Edizione digitale}

URL: https://journals.openedition.org/studifrancesi/46245

DOI: 10.4000/studifrancesi.46245

ISSN: 2421-5856

\section{Editore}

Rosenberg \& Sellier

\section{Edizione cartacea}

Data di pubblicazione: 1 octobre 2007

Paginazione: 474

ISSN: 0039-2944

\section{Notizia bibliografica digitale}

Emanuele Kanceff, «Saint-John Perse, Uccelli», Studi Francesi [Online], 152 (LI | II) | 2007, online dal 30 novembre 2015, consultato il 24 novembre 2021. URL: http://journals.openedition.org/studifrancesi/ 46245 ; DOI: https://doi.org/10.4000/studifrancesi.46245

Questo documento è stato generato automaticamente il 24 novembre 2021.

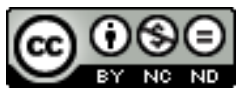

Studi Francesi è distribuita con Licenza Creative Commons Attribuzione - Non commerciale - Non opere derivate 4.0 Internazionale. 


\title{
Saint-John Perse, Uccelli
}

\author{
Emanuele Kanceff
}

\section{NOTIZIA}

SAINT-JOHN PERSE, Uccelli, a cura di Anna BATTAGLIA, Alessandria, Edizioni dell'Orso, 2006

(Coll. "Biblioteca mediterranea" diretta da Pablo Luis Avila e Giancarlo DEPRETIS, Sez.

"Poesia", 6), pp. 148.

1 I bibliografi resteranno forse perplessi nel redigere la descrizione di questo libretto, formalmente di Saint-John Perse, in cui la presenza dello scrittore è decisamente minoritaria. Lo diciamo non certo con rammarico, di fronte a quanto è ascrivibile al "curatore", Anna Battaglia, la cui opera non si è limitata alla traduzione del testo francese pubblicato a fronte. Traduzione a parte, molto giusta nei toni e negli esiti, rimane questa messa a punto su Oiseaux che fa del libro un altro libro, un saggio puntuale in cui storia letteraria, esercizio critico, sensibile lettura poetica si intrecciano indissolubilmente. Nonostante che ormai gli studi attorno a Perse e alla sua opera siano avanzati di molto, questa "leggera fatica" di Anna Battaglia non è affatto superflua per gli specialisti e resterà un punto solido nel cammino critico sullo scrittore antillese e mediterraneo. 